\title{
Unilateral pleural effusion complicating central venous catheterisation
}

\author{
P Madhavi, R Jameson, M J Robinson
}

\begin{abstract}
Acute respiratory distress developed in two preterm babies because of unilateral hydrothorax secondary to the migration of a central venous catheter into the pulmonary vasculature. Prompt recognition of the problem and rapid treatment are essential and life saving. This complication of intravenous alimentation catheters has not been previously reported in the neonatal age group.
\end{abstract}

(Arch Dis Child Fetal Neonatal Ed 2000;82:F248-F249)

Keywords: pleural effusion; central venous catheter; preterm; parenteral nutrition

\section{Case reports}

A 700 g girl was delivered vaginally at 26 weeks gestation and underwent mechanical ventilation for surfactant deficient lung disease and later for poor respiratory effort. She was fed parenterally through peripheral lines. At 16 days of age when vascular access became a problem, a 27 gauge silastic catheter (Vygon (UK) Ltd, Cirencester, Gloucestershire GL7 1PT, UK) was passed into the right atrium through the right external jugular vein, and its position confirmed radiologically. On the 19th day she suddenly became hypoxic (arterial $\mathrm{Po}_{2} 30 \mathrm{~mm} \mathrm{Hg}$ ) and failed to respond to increased ventilatory support. Radiographic contrast examination disclosed a right pleural effusion and showed the tip of the catheter to be in the right pulmonary artery (fig 1). About $15 \mathrm{ml}$ straw coloured fluid was aspirated from the right pleural cavity, and the central venous catheter was removed. Oxygenation improved dramatically and an uneventful recovery made.

A $900 \mathrm{~g}$ boy was delivered vaginally at 25 weeks gestation and ventilated for three days for surfactant deficient lung disease. After a
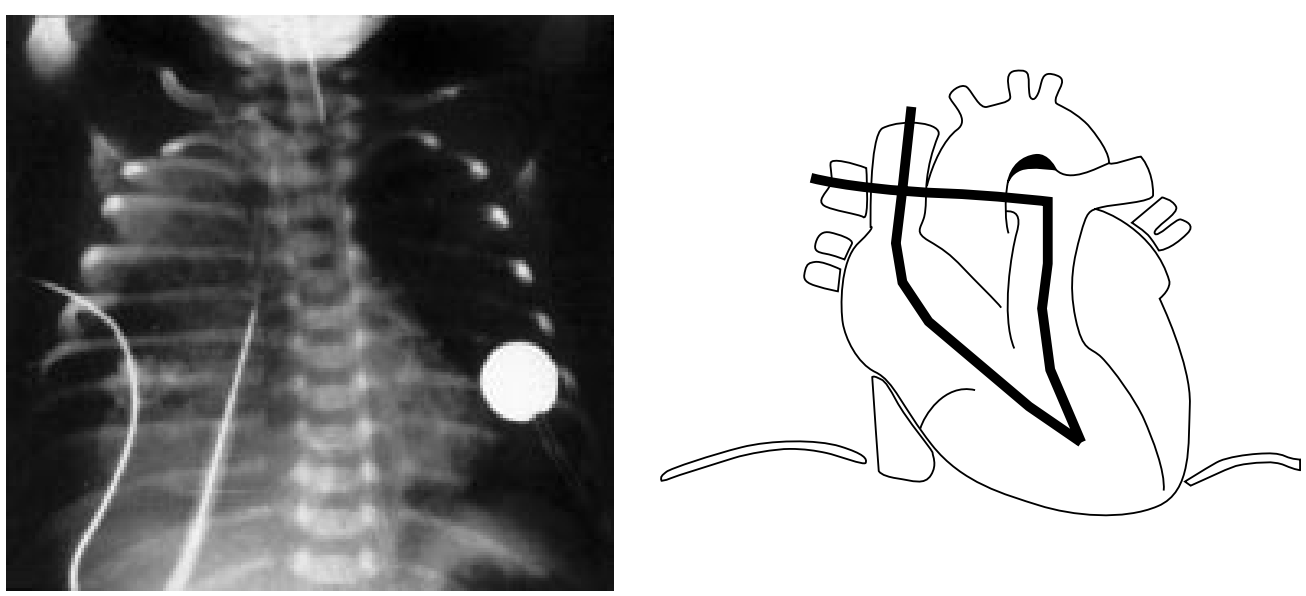

Figure 1 Chest $x$ ray picture with contrast and line diagram showing a right pleural effusion and the tip of the catheter in the right pulmonary artery.

period of continuous positive airways pressure, he was reventilated for apnoea secondary to sepsis. He was fed parenterally from day 2 through peripheral veins, and on day 3 a 27 gauge silastic catheter was passed into the right atrium through the left saphenous vein. On day 10 acute respiratory distress which failed to respond to increased ventilatory support developed. A chest radiograph documented a large right hydrothorax, with the catheter tip in the right pulmonary vein. Drainage of the hydrothorax and withdrawal of the catheter into the right atrium was accompanied by prompt relief of respiratory distress. A subsequent chest radiograph showed lung clearing, and six days later the catheter was removed without complication.

In each case the central venous catheter was secured with $2 \mathrm{~cm}$ Steri-strips (3M, Loughborough, Leicestershire LE11 1EE, UK) crisscrossed under the catheter close to the insertion site. An additional Steri-strip overlapped the insertion site. The entire length of catheter was loosely coiled and secured to the skin using $3 \mathrm{~cm}$ Steri-strips. A $2 \times 2 \mathrm{~cm}$ gauze sponge was placed under the hub. A transparent semipermeable dressing was fitted over the insertion site and the entire coiled catheter and the hub.

\section{Discussion}

Parenteral nutrition through central lines has been used in the management of small sick newborn infants since $1968 .{ }^{1}$ A series of complications have been reported ${ }^{2-4}$ including sepsis, thrombosis, vessel perforation, cardiac tamponade, ${ }^{5}$ and chemical pneumonitis. ${ }^{6}$ In two previously reported cases, unilateral pleural effusions occurred secondary to perforation of an intrathoracic vessel. ${ }^{7}$ Right sided

Hope Hospital, Salford M6 8HD, UK

P Madhavi

M J Robinson

Correspondence to: Dr Robinson, Hope Hospita NICU, Salford M6 8HD,

email: mrobinson@ gen.srht.nwest.nhs.uk 
hydrothorax in extremely low birthweight infants secondary to the retrograde passage of a central venous catheter into the lymphatic duct or erosion of the internal jugular vein has been described. ${ }^{8}$

In these two cases the catheter position in the right atrium was confirmed radiologically. In the first case, the catheter subsequently passed through the right ventricle and wedged in the right pulmonary artery. The development of hydrothorax in this case was not related to fluid overload, as the total parenteral nutrition flow rate of $3.3 \mathrm{ml} / \mathrm{h}$ was trivial compared with the pulmonary blood flow of $180 \mathrm{ml} / \mathrm{m}^{2} / \mathrm{min}$ (indicating a flow rate down each pulmonary artery of $1080 \mathrm{ml} / \mathrm{h}$ ). The osmolarity of the total parenteral nutrition was 1319 mosm/l. The development of hydrothorax may have been due to hyperosmotic endothelial damage leading to increased vascular permeability. There was no evidence of catheter perforation of the vessel wall, nor of a slow erosion of the vessel, as no blood or intralipid was obtained at thoracocentesis.

In the second case, the long saphenous catheter passed via the foramen ovale through the left atrium and into a right pulmonary vein. The development of hydrothorax in this case, we suggest, is related to increased hydrostatic pressure in a pulmonary vein with resultant shift across the endothelium. There was no evidence of vessel perforation.

It is interesting to note that the inferior vena cava catheter preferentially passed across the foramen ovale to the left atrium, and the superior vena cava catheter traversed the tricuspid valve into the right ventricle and pulmonary arterial trunk, as does fetal blood flow.

The resultant pleural transudate led to acute respiratory distress. After removal of pleural fluid and withdrawal of the central venous catheter, there was a rapid and complete recovery.

CONCLUSION

These two cases underline the necessity for good skin fixation to prevent onward catheter movement and the importance of reassessment of the catheter position should there be any unexplained clinical deterioration during parenteral nutrition.

\section{Recommendation}

The ideal position for central venous catheters is at the junction of the superior or inferior vena cava and the right atrium. ${ }^{9}$ To prevent onward catheter movement, we suggest: (a) four or five overlapping $2 \mathrm{~cm}$ Steri-strips be applied starting close to the insertion site to secure the catheter to the skin; $(b)$ a square of transparent semipermeable dressing be fitted over the insertion site and Steri-strips; (c) the entire length of the catheter is secured to the patient (the catheter is initially loosely coiled and later secured to the skin using narrow strips of transparent semipermeable dressings); (d) a single piece of tape is criss-crossed under the hub and over the wings of the catheter to stabilise the connection between catheter and hub; (e) a $2 \times 2 \mathrm{~cm}$ gauze sponge is placed under the hub and taped, ensuring that the catheter connection of the hub is not kinked.

Transparent dressing or skin closure tapes should not be allowed to encircle the extremity completely, as, even with mild venous congestion, such a dressing would act as a tourniquet.

1 Dudric SJ, Wilmore DW, Vars HM, Rhoads JE. Longterm total parenteral nutrition with growth, development and positive nitrogen balance. Surgery 1968;64:132-42.

2 Milluihill SJ, Fonkalsrud EW. Complications of superior versus inferior vena cava occlusion in infants receiving central total parenteral nutrition. Fournal of Paediatric Surgery $1984 ; 19: 752-7$

3 Kelly MA, Finer NN, Dubar LG. Fatal neurological complication of parenteral feeding through a central vein complication of parenteral feeding through a central vein 1984;138:352-3.

4 Stine MJ, Harris H. Subdural collection of intravenous fat emulsion in a neonate. Clin Pediatr (Phila) 1985;24:40-1. 5 George P, Giacoia MD. Cardiac tamponade and hydrothorax as complications of central venous parenteral nutrition in infants. Fournal of Parenteral and Enteral Nutrition 1991;15:110-13.

6 Rubin S, Hewson P, Roberton NRC. Pulmonary complications of total parenteral nutrition in a neonate. $\mathcal{F} R$ Soc $\mathrm{Med}$ 1986;79:545-7.

7 Knight L, Tobin J, L'heureux P. Hydrothorax: a complication of hyperalimentation with radiologic manifestations. Radiology 1974;111:693-5.

8 John H, Seguin MD. Right-sided hydrothorax and central venous catheter in extremely low birthweight infants. $A m \mathcal{F}$ Perinatol 1992;9:154-8.

9 Fletcher MA, Mhairi G (eds). MacDonald atlas of procedures in neonatology. Philadelphia: Lippincott, 1993:202-19. 